\title{
Respiratory Protective Equipment for Healthcare Providers During Coronavirus Pandemic: "Nec Temere, Nec Timide"
}

\author{
H. Bengü Çobanoğlu ${ }^{1}$ (D), Görkem Eskiizmir ${ }^{2}$ (D), Mustafa Kürşat Gökcan ${ }^{3}$ \\ ${ }^{1}$ Department of Otorhinolaryngology-Head and Neck Surgery, Karadeniz Technical University School of Medicine, Trabzon, \\ Turkey \\ Review ${ }^{2}$ Department of Otolaryngology-Head and Neck Surgery, Celal Bayar University School of Medicine, Manisa, Turkey \\ ${ }^{3}$ Department of Otorhinolaryngology-Head and Neck Surgery, Ankara University School of Medicine, Ankara, Turkey
}

\begin{abstract}
In otorhinolaryngology-head and neck surgery, there are several routine and surgical procedures applied to the upper airway that generate droplets and/or aerosols. Therefore, otorhinolaryngology-head and neck surgeons are at higher risk of being exposed to viral content. The COVID-19 pandemic has shaken the world with approximately 30 million affected cases and more than 900.000 deaths officially reported in more than 200 countries/regions from March $11^{\text {th }}$, 2020 to date (September 12 ${ }^{\text {th }}, 2020$ ). All healthcare
\end{abstract}

ORCID iDs of the authors: H.B.Ç. 0000-0003-3701-1697; G.E. 0000-0002-3125-8288; M.K.G. 0000-0002-4160-7349

Cite this article as: Çobanoğlu HB, Eskiizmir G, Gökcan MK. Respiratory Protective Equipment for Healthcare Providers During Coronavirus Pandemic: "Nec Temere, Nec Timide". Turk Arch Otorhinolaryngol 2020; 58(4): 268-73.

\section{Corresponding Author:}

H. Bengü Çobanoğlu; benguyc@gmail.com

Received Date: 17.09.2020

Accepted Date: 03.12 .2020

Content of this journal is licensed under a Creative Commons Attribution 4.0 International License. Available online at www.turkarchotolaryngol.net

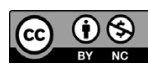

D0l: 10.5152/ta0.2020.5999

\section{Introduction}

An infectious respiratory disease caused by severe acute respiratory coronavirus- 2 syndrome (SARS-CoV2) which emerged at the end of 2019 has resulted in a worldwide health crisis known as the Coronavirus-2019 disease (COVID-19). On March $11^{\text {th }}, 2020$, the World Health Organization (WHO) issued a global pandemic warning for COVID-19 (1). Coronavirus-2019 is a highly contagious virus with an $R O$ value of 1.4-5.5 (2). It is known that the transmission routes of SARS CoV-2 are direct (person-to-person), indirect (formite), and droplet $(>5 \mathrm{~mm})$ contacts. Currently, it is known that the highest viral load of SARS$\mathrm{CoV}-2$ is in sputum and upper airway secretions (3). The virus is predominantly spread by droplets. Droplet transmission is via respiratory particles that are larger than $5 \mu \mathrm{m}$ in diameter and have a tendency to travel less than $1 \mathrm{~m}$. Therefore, a limit of $2 \mathrm{~m}$ for contact is mandatory. Some authors also advocated that SARS CoV-2 is transmitted by viable viruses in aerosol particles $(<5 \mathrm{~mm})$ that suspend in the air (airborne transmission) (4-6). providers working at the frontlines of the fight against the COVID-19 are at risk of contracting the virus. In this review, we discuss the efficacy of the different types of respiratory protective equipment and remind about the surgery-based respiratory protection strategies in otorhinolaryngology and head and neck surgeries in the light of the latest literature.

Keywords: Otorhinolaryngology, COVID-19, contagious infection, healthcare provider, personal protective equipment, virus disease
To date (September $12^{\text {th }}, 2020$ ), approximately 30 million patients with COVID-19 were officially reported in more than 200 countries/regions with more than 900.000 deaths. All health-care providers (HCPs) who are working at the frontlines of the fight against COVID-19 are at risk of being infected the virus. Unfortunately, more than 3,000 HCPs in China, 9,282 HCPs in the U.S., and 20\% of HCPs in Italy have been infected $(7,8)$. As seen in the SARS outbreak in 2003, personal protective equipment (PPE) is known to be effective in reducing nosocomial infection risks (9). Although PPE usage can vary according to national resources, the Center for Disease Control and Prevention (CDC) and the WHO recommended that HCPs should wear PPEs against droplet-based transmission. Unfortunately, different research showed that HCPs are at high risk of self-contamination while removing or disposing of the PPE $(10,11)$. Moreover, several medical procedures may generate aerosols that might travel over distances beyond $2 \mathrm{~m}$, even though the airborne behavior of COVID-19 is uncertain (12). 
In otorhinolaryngology-head and neck surgery, there are several routine and surgical procedures applied to the upper airway that generate droplets and/or aerosols. Therefore, otorhinolaryngology-head and neck surgeons are at higher risk of being exposed to viral content. Respiratory protection should be ensured to correspond to the potential level of airborne transmission to reduce the risk of contagion during aerosol-generating procedures $(13,14)$.

Currently, different types of masks (surgical and filtering facepiece $[\mathrm{FFP}]$ masks) and equipment (elastomeric respirators, powered air-purifying respirator [PAPR]) are used for respiratory protection. Unfortunately, our knowledge about these masks and equipment is limited, and this may lead to confusion about using the appropriate option. Therefore, we aimed to review the efficacy of different types of masks and respiratory protective equipment and remind about the surgery-based respiratory protection strategies in otorhinolaryngology and head and neck surgeries.

\section{Surgical Mask}

A surgical mask is not a respiratory protective equipment, even though it is an effective equipment for the protection of patients against droplets of HCPs and vice versa. It adapts loosely to the face and forms a barrier against droplets. However, it is not designed to protect the wearer against airborne infectious agents. It is known from yearslong experiences that the test pathogen for the effectiveness of a surgical mask is the Staphylococcus aureus. When the sizes of SARS-CoV-2 and Staphylococcus aureus are compared, SARS-CoV-2 is 10-50 times smaller. Therefore, it is structurally not an ideal barrier for COVID-19 contagion. However, it is noteworthy that the size may not be as critical as it is assumed, because the viruses are transported by droplets (15).

\section{Respiratory Protective Equipment}

Respiratory protective equipment is any mask or device that is designed for the protection of the wearer from different airborne hazards and infectious agents. Respiratory protective equipment

\section{Main Points}

- Otorhinolaryngology-head and neck surgeons are at higher risk of being exposed to viral content. Respiratory protection should be ensured to correspond to the potential level of airborne transmission to reduce the risk of contagion during an aerosol-generating procedure.

- A surgical mask is effective against the droplet transmission of infectious agents; however, it does not protect HCPs against airborne transmission.

- Respiratory protective equipment is highly recommended when the risk of aerosol exposure is high.

- Air-purifying respirators are the best option for the HCPs during aerosol-generating procedures. Even though all air-purifying respirators can protect HCPs against aerosols, it is noteworthy that non-powered air-purifying respirators require a "respirator-fit test" before usage.

- An eye shield and eye-goggles are also recommended for eye protection for HCPs who use filtering facepiece masks or partial-face elastomeric respirators. is divided into two groups: air-supplying and air-purifying respirators (Figure 1).

Air-supplying respirators are specially designed systems or devices that provide clean breathing air to the wearer and isolate the wearer from the environment's atmosphere. Therefore, they have the highest respiratory safety level. However, they have limited use in medical applications $(5,16)$.

Air-purifying respirators are different types of masks and devices that can clean the environment's air, thereby protect the wearer from airborne hazards and infectious agents. Air-purifying respirators are widely used in medical applications particularly during the COVID-2019 pandemic.

\section{Air-supplying Respirators}

Air-supplying respirators can be used in oxygen-deficient environments or against airborne hazards (toxic fumes) and infectious agents. There are two types of air-supplying respirators: supplied-air respiratory system and self-contained breathing apparatus (Figure 1) (16).

\section{Supplied-air Respiratory Systems}

Supplied-air respiratory systems provide clean and breathable air to the wearer from an air supply through an airline. They are especially used in biosafety level 4 laboratories that deal with highly infective agents such as the Ebola virus, the Marburg virus, or the Lassa virus (17).

\section{Self-contained Breathing Apparatus}

Self-contained breathing apparatus utilize clean and breathable air from a tank that is generally carried by the wearer. These types of equipment are used by special personnel who work in oxygen-deficient environments or are exposed to highly toxic and hazardous fumes (17).

\section{Air-purifying Respirators}

Air-purifying respirators are divided into two groups according to power supply: non-powered and powered (Figure 1).

\section{Non-powered air-purifying Respirators}

Non-powered air-purifying respirators do not require any power supply. However, all wearers should undertake "respirator

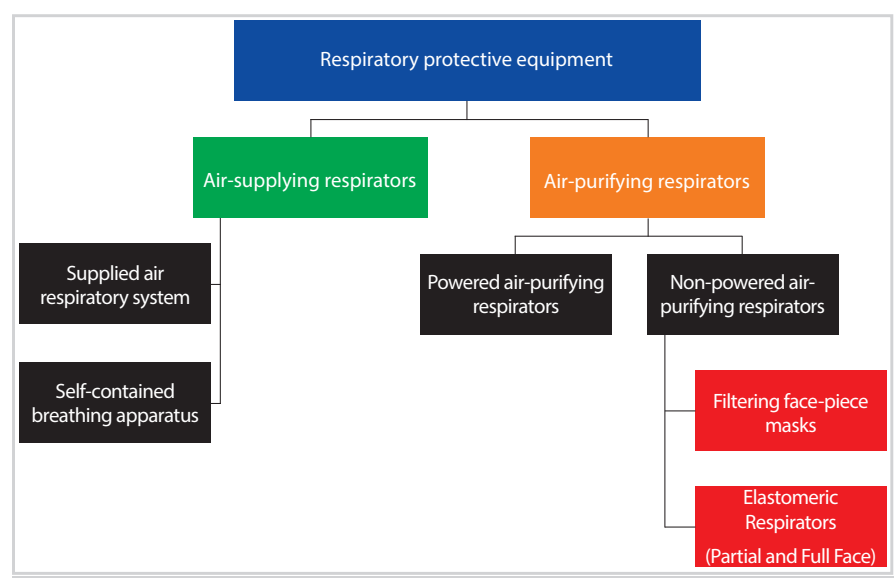

Figure 1 . The classification of respiratory protective equipment 
fit-testing" before usage (18). There are two types of non-powered air-purifying respirators: filtering facepiece masks and elastomeric respirators (Figure 1).

\section{Filtering facepiece masks}

Filtering facepiece masks are classified based on their filtering performance of the particles $>0.3 \mu \mathrm{m}$ as FFP1, FFP2 and FFP3. Filtering performance of FFP1, FFP2 and FFP 3 can be defined as $>80 \%,>94 \%$, and $>99 \%$, respectively (17).

The N95 designation stands for "under test conditions" (certified under 42 CFR 84 of National Institute for Occupational Safety and Health and the United States CDC) the respirator blocks at least $95 \%$ of solid and liquid aerosol test particles. Recent studies demonstrated that FFP2 (N95 equivalent) and FFP3 (N99 equivalent) masks are highly protective against MERS, SARS, and COVID-19 when compared with surgical masks $(16,19)$ (Figure 2). The WHO warns that FFP2 and FFP3 masks can be effectively used up to 4 hours. All FFP2 and FFP3 masks should fit properly on to the face to create a seal.

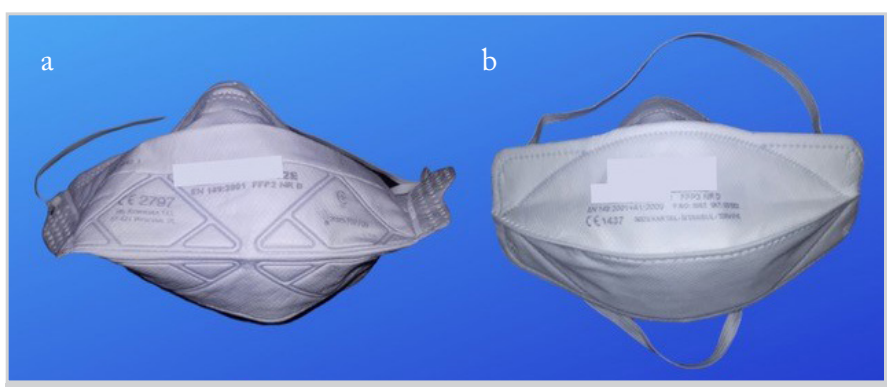

Figure 2. a, b. Filtering facepiece masks (a) FFP2 and (b) FFP3

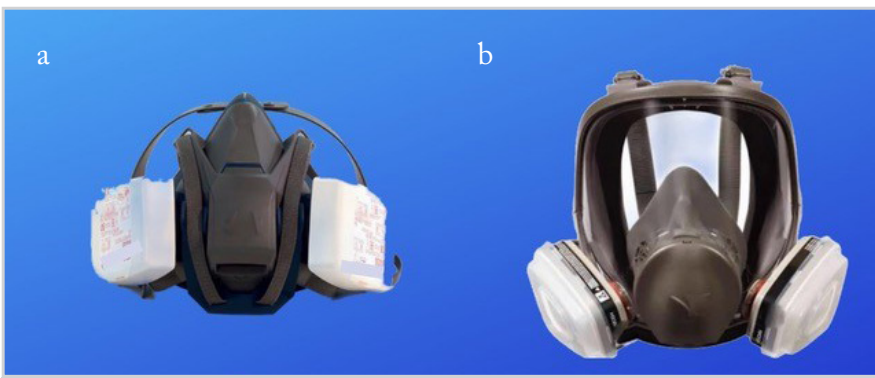

Figure 3. a, b. Elastomeric respirators (a) partial-face, (b) full-face

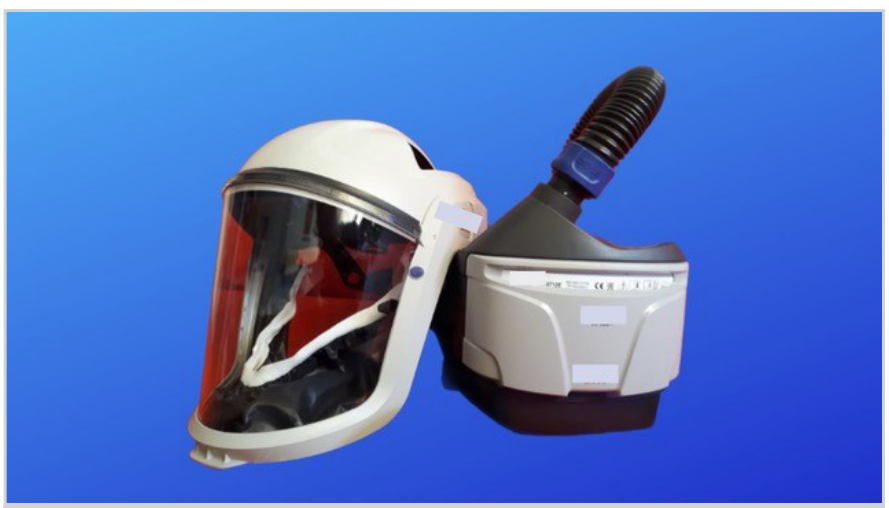

Figure 4. Powered air-purifying respirator
One of the main reasons for intolerance to FFP 2 and 3 usage is breathing problems. Therefore, some FFP 2 and 3 masks may have a breathing valve (ventilation). Breathing (especially during expirium) is much easier while using FFP masks with a breathing valve. However, users may still spread droplets, even though an FFP mask with a breathing valve may effectively protect against SARS-CoV-2 transmission. Therefore, FFP masks with a breathing valve should be used attentively in healthcare settings, and anyone using an FFP mask with a breathing valve should also wear a covering surgical mask (20).

The shortage of FFP masks is a major problem worldwide. Therefore, the re-usage of disposable FFP masks is one of the hot topics during this pandemic. To date, no research or experiments have been published involving COVID-19 and FFP masks. A variety of decontamination methods have been proposed, such as UV light, hydrogen peroxide vapor, exposure to heat and steam, and leaving the mask sit for several days before reusing. The CDC provided a statement about the decontamination of FFP masks, recommending HCPs to consider using either Ultraviolet- $\mathrm{C}$, vaporized hydrogen peroxide, or moist heat in crisis conditions (21-23).

\section{Elastomeric Respirators (Partial or Full-Face)}

These respirators were originally designed for pest control companies. They started to be used during surgeries or high-risk procedures during the pandemic. They have good respiratory protection and breathing is relatively easy when compared with FFP masks. They can be worn in partial or full-face (Figure 3). Despite similar respiratory protection, full-face elastomeric respirators also protect the eyes. However, poor communication quality when wearing these respirators and filter replacement are their main disadvantages (16).

\section{Powered Air-purifying Respirator}

A PAPR is defined as a respirator that filters out the contaminants in the air using a battery-operated blower to maintain clean air to the user through a tight-fitting respirator, a loose hood, or a helmet (24) (Figure 4). Powered air-purifying respirators usually have a full facepiece part and loose-fitting hoods attached to waist-mounted belt batteries. They are specific for high hazard procedures. In most PAPRs, high-efficiency particulate air (HEPA) filters are used. They can thereby filter at least $99.7 \%$ of the particles $0.3 \mu \mathrm{m}$ in diameter (25). Moreover, the hoods of PAPRs are oil-proof and can be useful for the protection of the eyes (26).

Powered air-purifying respirators are considered more protective than the FFP masks in terms of the level of respiratory protection. The aerosol concentration inhaled by HCPs are reduced to $1 / 25^{\text {th }}$ in PAPRs, and $1 / 10^{\text {th }}$ in respirators, respectively. A systemic review with low-quality evidence demonstrated that PAPR might provide better protection in $\mathrm{HCPs}$ when compared with alternative respiratory protection devices. The same study also showed that satisfaction was higher concerning thermal comfort; however, lower for audibility and mobility (24). The advantages and disadvantages of FFP2/3 masks, respirators and PAPR are shown in Table 1. 
Table 1. Advantages and disadvantages of FFP2/3 masks, elastomeric respirators and PAPR

\begin{tabular}{|c|c|c|c|}
\hline & FFP2/3 mask & $\begin{array}{l}\text { Elastomeric respirators } \\
\text { (full- or partial-face) }\end{array}$ & PAPR \\
\hline $\begin{array}{l}\text { Assigned protection factor } \\
\text { (respiratory protection) }\end{array}$ & 10 & $10-25$ & $25-1,000$ \\
\hline Patient perspective & Hard to recognize the physician & $\begin{array}{l}\text { Able to recognize the physician } \\
\text { (better for partial face respirator) }\end{array}$ & Able to recognize the physician \\
\hline Mask-fit test & Required & Not necessary & Not necessary \\
\hline Face and eye protection & $\begin{array}{l}\text { No (extra goggles and face shield } \\
\text { required) }\end{array}$ & $\begin{array}{l}\text { Variable (extra goggles and face } \\
\text { shield required for partial face } \\
\text { respirator) }\end{array}$ & Yes \\
\hline Headlight usage & Possible & $\begin{array}{l}\text { Possible (particularly for partial } \\
\text { face respirators) }\end{array}$ & Not possible \\
\hline Breathing discomfort & High & Intermediate & Low \\
\hline Perspiration discomfort & High & Low & Low \\
\hline Weight-related discomfort & No & No & Yes \\
\hline Reusable & No & Yes & Yes \\
\hline Filter replacement & No & Required & Required \\
\hline Cleaning and Decontamination & Not recommended & Required & Required \\
\hline Noise-related problem & No & No & Yes (mild to moderate) \\
\hline Charging problem & No & No & Yes \\
\hline Communication problem & Yes (mild to moderate) & Yes (moderate to high) & Yes (moderate to high) \\
\hline Interference with occupational activities & Yes (mild) & Yes (moderate) & Yes (moderate) \\
\hline Doffing and Donning & Easy & Easy & Complicated \\
\hline Facial skin conditions (scar, bruise, acne) & Yes, particularly in the long term & Yes, particularly in the long term & No \\
\hline Environmental pollution & High risk & Low risk & Low risk \\
\hline Economic burden & Low cost & Moderate cost & Expensive \\
\hline
\end{tabular}

FFP2/3: filtering facepiece mask 2/3; PAPR: Powered air-purifying respirators

\section{Respiratory Protective Equipment for Aerosol-Generating Surgical Procedures}

During the COVID-19 pandemic, all otorhinolaryngology-head and neck surgeons must be cautious against aerosol-generating surgical procedures. In this section we would like to briefly review these surgical procedures in regard of the appropriate respiratory protective equipment.

\section{Tracheotomy}

In each department, a selected otorhinolaryngology-head and neck surgeon should be the primary contact person for all COVID-19 tracheotomy consultations (27). If tracheotomy is indicated for a patient with COVID-19, it is controversial whether to perform an open surgical tracheotomy or a percutaneous dilatational tracheotomy to minimize aerosol generation. In our opinion, percutaneous tracheotomy with mini-incision seems more reliable in patients with COVID-19; however, it should be decided individually. During this procedure, all HCPs should wear head cover, PAPR, gown, and gloves. Tracheotomy might be postponed for patients with COVID-19 if PAPR are not available. Properly fitting FFP2/3 masks are mandatory in case of PAPR shortage (28).

\section{Pediatric Otorhinolaryngology Surgeries}

The appropriate PPEs for a pediatric patient for a surgical intervention (peritonsillar abscess drainage, post-tonsillectomy hemorrhage, acute airway obstruction, airway or esophageal foreign body, any trauma with significant soft tissue injury or airway obstruction, complicated acute otitis media or complicated mastoiditis, nasal endoscopy for foreign body, endonasal skull base surgery for cranial neuropathies or pituitary apoplexy) is not clear (29). However, the rational approach and techniques are discussed below.

In the above-mentioned surgical procedures, cold steel instrumentation should be preferred for patients with unknown, suspected, or positive COVID-19 to reduce aerosol generation. Respiratory protective equipment must include an FFP2/3 mask, or PAPR (preferred) $(29,30)$.

\section{Sinonasal Surgeries}

In patients with positive COVID-19 or unknown status, the use of suction electrocautery, microdebriders, drills and balloons, should be limited to minimize the dissemination of aerosolized viral particles. Patel et al. (31) reported COVID-19 transmission to surgical staff following microdebrider use. Otorhinolaryngology-head and neck surgeons should prefer cold steel instrumentation for sinus surgeries when possible. Because of the high transmission risk, enhanced PPE, preferably PAPR, should be used for any sinonasal procedure in patients with unknown, suspected, or positive COVID-19 status $(32,33)$. If microde- 
briders or high-speed powered instrumentations are required, the use of PAPRs is strongly recommended $(34,35)$.

\section{Otologic Emergencies}

Unless facial paralysis is present, tympanomastoid surgery in complicated acute mastoiditis may be postponed until COVID-19 test results are received. The use of PAPR is recommended if high-speed drills used in these procedures $(29,36)$. FFP2/3 masks are the second-line respiratory protective equipment.

\section{Laryngopharyngeal Surgeries}

As most laryngopharyngeal surgeries carry a high risk of aerosol generation, elective surgeries can be postponed. There are studies in the literature confirming that lasers, powered electrocautery devices, which can produce blood-containing aerosols and smoke plumes, can contain viruses and bacteria (37-39). Emergency laryngopharyngeal surgeries should be performed using PAPR or FFP2/3 masks.

Peer-review: Externally peer-reviewed.

Author Contributions: Concept - H.B.Ç., G.E., M.K.G.; Design - H.B.Ç., G.E., M.K.G.; Supervision - H.B.Ç., G.E., M.K.G.; Resources: M.K.G.; Materials - G.E.; Data Collection and/or Processing - H.B.Ç.; Analysis and/or Interpretation - M.K.G.; Literature Search - H.B.Ç.; Writing - H.B.Ç.; Critical Reviews - G.E.

Conflict of Interest: The authors have no conflicts of interest to declare.

Financial Disclosure: The authors declared that this study has received no financial support.

\section{References}

1. World Health Organization (WHO). Coronavirus Disease 2019 (COVID-19): Situation Report-146. Geneva, Switzerland: 2020.

2. Chen J. Pathogenicity and transmissibility of $2019-\mathrm{nCoV}$-a quick overview and comparison with other emerging viruses. Microbes Infect 2020; 22: 69-71.

3. Wang W, Xu Y, Gao R, Lu R, Han K, Wu G, et al. Detection of SARS-CoV-2 in different types of clinical specimens. JAMA 2020; 323: 1843-4.

4. Asadi S, Bouvier N, Wexler AS, Ristenpart WD. The coronavirus pandemic and aerosols: Does COVID-19 transmit via expiratory particles? Aerosol Sci Technol 2020; 54: 635-8.

5. The Lancet. COVID-19: protecting health-care workers. Lancet 2020; 395: 922.

6. CDC COVID-19 Response Team. Characteristics of health care personnel with COVID-19 - United States, February 12-April 9, 2020. MMWR Morb Mortal Wkly Rep 2020; 69: 477-81.

7. Zhan M, Qin Y, Xue X, Zhu S. Death from Covid-19 of 23 health care workers in China. N Engl J Med 2020; 382: 2267-8.

8. Chan JYK, Wong EWY, Lam W. Practical aspects of otolaryngologic clinical services during the 2019 novel coronavirus epidemic: an experience in Hong Kong. JAMA Otolaryngol Head Neck Surg 2020; 146: 519-20.

9. Seto WH, Tsang D, Yung RW, Ching TY, Ng TK, Ho M, et al. Effectiveness of precautions against droplets and contact in prevention of nosocomial transmission of severe acute respiratory syndrome (SARS). Lancet 2003; 361: 1519-20.
10. Suen LKP, Guo YP, Tong DWK, Leung PHM, Lung D, Ng MSP, et al. Self-contamination during doffing of personal protective equipment by healthcare workers to prevent Ebola transmission. Antimicrob Resist Infect Control 2018; 7: 157.

11. Lim SM, Cha WC, Chae MK, Jo IJ. Contamination during doffing of personal protective equipment by healthcare providers. Clin Exp Emerg Med 2015; 2: $162-7$.

12. van Doremalen N, Bushmaker T, Morris DH, Holbrook MG, Gamble A, Williamson BN, et al. Aerosol and surface stability of SARS-CoV-2 as compared with SARS-CoV-1. N Engl J Med 2020; 382: 1564-7.

13. Cook TM. Personal protective equipment during the coronavirus disease (COVID) 2019 pandemic - a narrative review. Anaesthesia 2020; 75: 920-7.

14. Tran K, Cimon K, Severn M, Pessoa-Silva CL, Conly J. Aerosol generating procedures and risk of transmission of acute respiratory infections to healthcare workers: a systematic review. PLoS One 2012;7: e35797.

15. Sommerstein R, Fux CA, Vuichard-Gysin D, Abbas M, Marschall J, Balmelli C, et al. Risk of SARS-CoV-2 transmission by aerosols, the rational use of masks, and protection of healthcare workers from COVID-19. Antimicrob Resist Infect Control 2020; 9: 100.

16. Tompkins BM, Kerchberger JP. Special article: personal protective equipment for care of pandemic influenza patients: a training workshop for the powered air purifying respirator. Anesth Analg 2010; 111: 933-45.

17. MacIntyre CR, Wang Q, Seale H, Yang P, Shi W, Gao Z, et al. A randomized clinical trial of three options for $\mathrm{N} 95$ respirators and medical masks in health workers. Am J Respir Crit Care Med 2013; 187: 960-6.

18. Ng K, Poon BH, Kiat Puar TH, Shan Quah JL, Loh WJ, Wong YJ, et al. COVID-19 and the risk to health care workers: a case report. Ann Intern Med 2020; 172: 766-7.

19. Chu DK, Akl EA, Duda S, alSolo K, Yaacoub S, Schünemann HJ, et al. Physical distancing, face masks, and eye protection to prevent person-to-person transmission of SARS-CoV-2 and COVID19: a systematic review and meta-analysis. Lancet 2020; 27: 1973-87.

20. MacIntyre CR, Wang Q. Physical distancing, face masks, and eye protection for prevention of COVID-19. Lancet 2020; 395: 19501.

21. Fisher EM, Shaffer RE. A method to determine the available UV-C dose for the decontamination of filtering facepiece respirators. J Appl Microbiol 2011; 110: 287-95.

22. Heckert RA, Best M, Jordan LT, Dulac GC, Eddington DL, Sterritt WG. Efficacy of vaporized hydrogen peroxide against exotic animal viruses. Appl Environ Microbiol 1997; 63: 3916-8

23. Centers for Disease Control and Prevention. Decontamination and Reuse of Filtering Facepiece Respirators. 2020 April. Available from: https:/www.cdc.gov/coronavirus/2019-ncov/hcp/ ppe-strategy/decontamination-reuse-respirators.html.

24. Licina A, Silvers A, Stuart RL. Use of powered air-purifying respirator (PAPR) by healthcare workers for preventing highly infectious viral diseases a systematic review of evidence. Syst Rev 2020; 9: 173 .

25. Centers for Disease Control and Prevention. Powered Air Purifying Respirators (PAPRs). Available from: https://www.cdc.gov/ coronavirus/2019-ncov/hcp/ppe-strategy/powered-air-purifying-respirators-strategy.html

26. Rengasamy S, Eimer BC, Shaffer RE. Comparison of nanoparticle filtration performance of NIOSH-approved and CE-marked particulate filtering facepiece respirators. Ann Occup Hyg 2009; 53: 117-28. 
27. Chao TN, Braslow BM, Martin ND, Chalian AA, Atkins J, Haas AR, et al. Tracheotomy in ventilated patients with COVID-19. Ann Surg 2020; 272: e30-e32.

28. Chen WQ, Ling WH, Lu CY, Hao YT, Lin ZN, Ling L, et al. Which preventive measures might protect health care workers from SARS? BMC Public Health. 2009;

29. Bann DV, Patel VA, Saadi R, Goyal N, Gniady JP, McGinn JD, et al. Best practice recommendations for pediatric otolaryngology during the COVID-19 pandemic. Otolaryngol Head Neck Surg 2020; 162: 783-94.

30. Brown KA, Morin I, Hickey C, Manoukian JJ, Nixon GM, Brouillette RT. Urgent adenotonsillectomy: an analysis of risk factors associated with postoperative respiratory morbidity. Anesthesiology 2003; 99: 586-95.

31. Patel ZM, Fernandez-Miranda J, Hwang PH, Nayak JV, Dodd R, Sajjadi H, et al. Letter: Precautions for Endoscopic Transnasal Skull Base Surgery During the COVID-19 Pandemic. Neurosurgery. 2020; 87: E66-E67.

32. Messner A. American Society of Pediatric Otolaryngology (ASPO) message from the president. 2020. Available from: https://www.entnet.org/sites/default/files/uploads/aspo_03-2320.pdf. Accessed March 23, 2020.

33. CMS adult elective surgery and procedures recommendations: limit all non-essential planned surgeries and procedures, including dental, until further notice. https://www.cms.gov/files/document/ covid-elective-surgery-recommendations.pdf Accessed March 21, 2020.

34. González-Bayón L, González-Moreno S, Ortega-Pérez G. Safety considerations for operating room personnel during hyperthermic intraoperative intraperitoneal chemotherapy perfusion. Eur J Surg Oncol 2006; 32: 619-24.

35. Ishihama K, Sumioka S, Sakurada K, Kogo M. Floating aerial blood mists in the operating room. J Hazard Mater 2010; 181: 1179-81.

36. Heikkinen T, Thint M, Chonmaitree T. Prevalence of various respiratory viruses in the middle ear during acute otitis media. N Eng1 J Med 1999; 340: 260-4.

37. Freitag L, Chapman GA, Sielczak M, Ahmed A, Russin D. Laser smoke effect on the bronchial system. Lasers Surg Med 1987; 7: 283-8.

38. Ferenczy A, Bergeron C, Richart RM. Human papillomavirus DNA in $\mathrm{CO} 2$ laser-generated plume of smoke and its consequences to the surgeon. Obstet Gynecol 1990; 75: 114-8.

39. Topf MC, Shenson, JA, Holsinger FC, Wald SH, Cianfichi LJ, Rosenthal EL, et al. Framework for prioritizing head and neck surgery during the COVID-19 pandemic. Head Neck 2020; 42: 1159-67. 